\title{
A novel autologous duraplasty in situ technique for the treatment of Chiari malformation Type I
}

\author{
*Lei Zhang, MD, Zhiqiang Yi, MD, Hongzhou Duan, MD, and Liang Li, MD \\ Department of Neurosurgery, Peking University First Hospital, Beijing, China
}

OBJECTIVE The purpose of this study was to introduce a novel autologous duraplasty procedure for the treatment of Chiari malformation Type I (CM-I).

METHODS The authors retrospectively reviewed data from patients who had been diagnosed with CM-I and had undergone suboccipital decompression and autologous duraplasty in situ or synthetic dural graft duraplasty; patients were treated in the authors' department between 2011 and 2014. All procedures were performed by the same surgeon. The 2 duraplasty methods were compared in terms of surgical factors and complications. The authors assessed the neurological outcome and MRI-documented syrinx size at the 6-month follow-up visit.

RESULTS Twenty-seven patients were enrolled in this study, 13 in the duraplasty in situ group and 14 in the synthetic dural graft duraplasty group. The results showed no significant differences between the duraplasty in situ and synthetic dural graft duraplasty groups in overall operative time (4.9 hours vs 4.1 hours; $p=0.070$ ), estimated blood loss (229 $\mathrm{ml}$ vs $254 \mathrm{ml} ; p=0.159$ ), and duration of hospital stay after the operation (13.5 days vs 12.8 days; $p=0.808$ ). In the duraplasty in situ group, 1 case of meningitis occurred (7.7\%). In the synthetic dural graft duraplasty group, the complications included 1 case of meningitis (7.1\%) and 1 CSF leak (7.1\%). The mean cost of hospitalization in the duraplasty in situ group (CNY 23,354) was significantly lower than that in the synthetic dural graft duraplasty group (CNY 29,385; $p=0.036$ ).

CONCLUSIONS Compared with synthetic dural graft duraplasty, autologous duraplasty in situ is a safe, effective, and cost-effective procedure for the treatment of $\mathrm{CM}-\mathrm{I}$. The long-term outcome of this procedure requires investigation.

http://thejns.org/doi/abs/10.3171/2016.1.JNS152161

KEY WORDS Chiari malformation Type I; duraplasty; decompression; surgical technique

A MPLE posterior fossa craniectomy with augmentative duraplasty is a widely accepted procedure in the surgical management of symptomatic patients with Chiari malformation Type I (CM-I). ${ }^{25}$ The keys to the success of cerebral operative procedures are to create ample decompression, regain normal CSF flow, and achieve effective watertight dural closure. . $^{7,19,20}$

There are many methods for further expansion of the posterior fossa during duraplasty. A dural graft should be used when a sufficient amount of the autogenous dura mater is not available after decompression. The ideal graft should generally be nonimmunogenic, nontoxic, rapidly integrated into native tissues, flexible, strong, easily suturable, and readily available. The graft should not cause inflammatory reactions or adhesions and should be able to be closed in a watertight fashion..$^{5,6,11,23}$ Allografts, xenografts, and synthetic dural substitutes are used for duraplasty, but all of these types of graft are associated with high complication rates. ${ }^{6}$ It is widely accepted that autologous tissues, such as autologous fascia lata, ligamentum nuchae, fat packings, and the pericranium, are the ideal dural graft substrates. ${ }^{1}$ However, obtaining these autologous tissues causes extra harm to the patient and requires extension of the incision or an additional incision. The optimal procedure should cause the least harm to the patient and should not use a synthetic dural graft.

Here, we introduce a new autologous duraplasty in situ procedure for CM-I decompression that is more cost-effective than synthetic dural graft duraplasty and less invasive than autologous dural graft duraplasty. We describe

ABBREVIATIONS BMI = body mass index; CM-I = Chiari malformation Type I; CNY = Chinese yuan; EBL = estimated blood loss; LOS = length of hospital stay . SUBMITTED September 15, 2015. ACCEPTED January 12, 2016.

* Drs. Zhang and Yi contributed equally to this work. 
our technique and the results of its application in 27 cases in our clinical center. To the best of our knowledge, this is the first report of the application of this technique.

\section{Methods \\ Patients}

Between 2011 and 2014, 31 patients who were preoperatively diagnosed with symptomatic CM-I underwent suboccipital decompression and either duraplasty in situ or synthetic dural graft duraplasty, which were performed by the senior surgeon (L.L.) who invented the duraplasty in situ technique at our institution. Of these patients, 3 treated with suboccipital decompression alone were excluded from the analysis, and 1 did not undergo a follow-up after discharge from the hospital. Among the remaining patients, 13 (3 men, 10 women) underwent surgery using the new technique, duraplasty in situ, and 14 (6 men, 8 women) underwent surgery using duraplasty in which a synthetic dural graft was placed. All data were retrospectively collected to evaluate this technique, including demographic data (age and sex), body mass index (BMI), preoperative symptom status, overall operative time, estimated blood loss (EBL), length of hospital stay (LOS) after the operation, hospital cost, and complications. CM-I was diagnosed clinically based on symptoms and radiologically based on preoperative MRI studies. All patients provided informed consent and were requested to return for follow-up in the outpatient department. Routine MRI scans were obtained 2 weeks and 6 months after surgery in all patients. We used neurological outcome and syrinx size on postoperative MRI to establish functional status at 6 months after surgery. The total hospital cost for each patient was calculated as the sum of the surgical, hospital, examination, and allied service costs.

\section{Operative Technique}

The patient was placed prone with the head flexed and secured in Mayfield pins after general anesthesia was administered. A suboccipital midline incision of $5 \mathrm{~cm}$ was made from the inion to the expected caudal extent of the decompression (Fig. 1A). The paraspinous musculature was separated along the avascular midline using self-retaining retractors. The foramen magnum, $\mathrm{C}-1$ lamina, and $\mathrm{C}-2$ spinous process were exposed, and an occipital craniectomy was performed (Fig. 1B). A bony decompression window $(3 \times 3 \mathrm{~cm})$ was created using a high-speed cutting drill and rongeur forceps (Fig. 1C). An approximately 2 -cm-wide portion of the C-1 arch was removed, and the superior margin of the $\mathrm{C}-2$ arch was partially removed in the rare cases in which the tonsillar herniation extended to the C-2 level (Fig. 1D). The technique is performed using the operating microscope; a $5 \times$ magnification is applied for a clear view of the operative site. Consequently, the outer layer of the dura was cut in a U-shaped fashion from the bottom of the $\mathrm{C}-2$ arch (Fig. 2A). The edge of the outer layer of the dura was elevated and gradually separated from the inner layer of the dura upwards using delicate dissection until the decompressive bony margin on the surface of the cerebellar hemispheres was reached
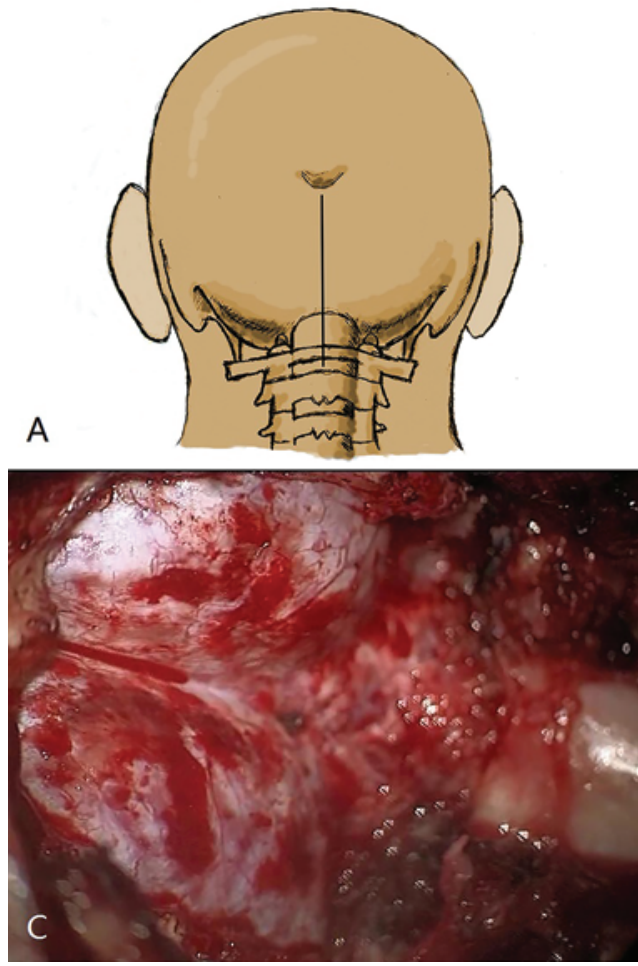
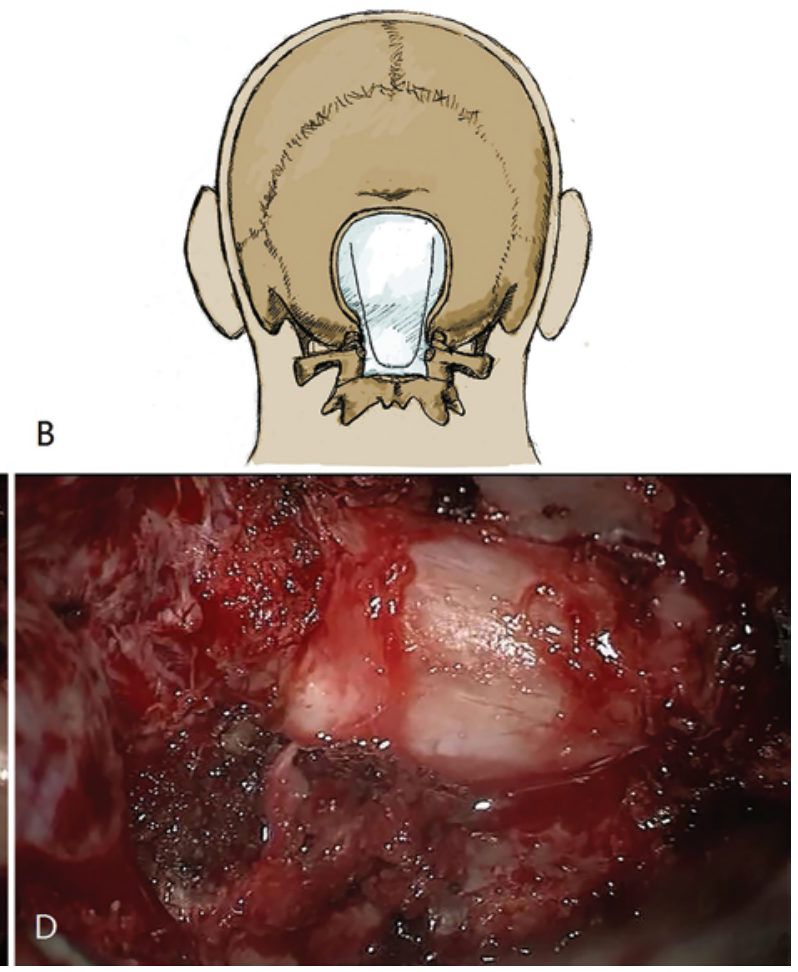

FIG. 1. Drawings and intraoperative photographs depicting the duraplasty in situ technique. A and B: Drawings show typical CM-I incision extending from the inion to the upper cervical spine and posterior fossa craniotomy. Copyright Lei Zhang. Published with permission. C and D: Bony decompression window of the occipital fossa with arches of C-1 and C-2 partially removed. Figure is available in color online only. 

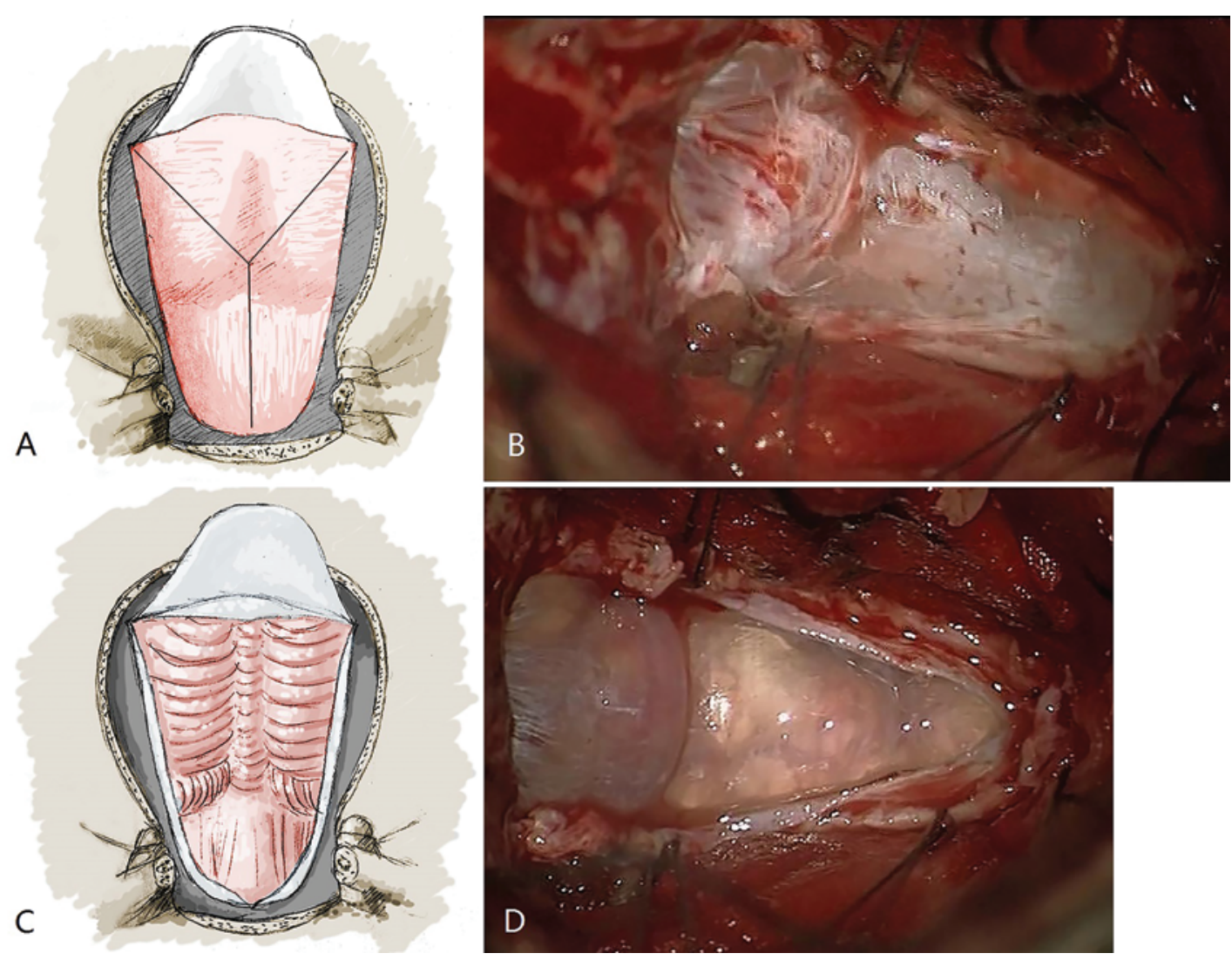

FIG. 2. Drawings and intraoperative photographs showing continuation of duraplasty in situ technique. A and B: A U-shaped outer layer incision is made, and the outer and inner layers of the dura are fully separated. C and D: A Y-shaped dural opening is created and the inner layer of the dura is opened while the arachnoid membrane is kept intact. A and C: Copyright Lei Zhang. Published with permission. Figure is available in color online only.

(Fig. 2B); we were careful to separate the dura through the natural space between the layers. If the 2 layers are difficult to separate, especially in older patients, one should begin with the easier part first and then deal with the more tightly adhered part. Small holes made in the dura during separation can be sutured with Prolene. Any bleeding between the 2 layers was resolved with cottonoid pressure, and in cases of dural shrinkage, bipolar coagulation was used as minimally as possible at the lowest intensity. Finally, a ligulate outer-layer dural flap was created. The inner layer of the dura was opened in a Y-shaped fashion while attempting to keep the arachnoid membrane intact (Fig. 2C and D). The ligulate outer-layer dural flap was deflected down and sutured to the Y-shaped margin of the inner layer using running sutures (Fig. 3A and B). Using this technique, the ligulate outer-layer dural flap was enlarged for augmentative duraplasty (Fig. 3C). Hemostasis was meticulously achieved, and a drainage tube was placed. Then, the surgical wound was closed in multiple layers.

\section{Statistical Analysis}

Categorical data were analyzed using Pearson's chisquare test. Continuous data were analyzed using the Student t-test. All analyses were performed with SPSS 22.0 software (IBM Corp.). A p value $<0.05$ was considered significant. Mean values are presented $\pm \mathrm{SD}$.

\section{Results}

Of the 31 patients initially considered for enrollment in this study, 3 underwent decompression without opening of the dura and 1 did not complete follow-up. Thus, 27 patients completed follow-up, and their data were included in the analyses. The demographic and clinical data are presented in Table 1. In the duraplasty in situ group, the mean age of the patients was $40 \pm 15$ years (range 11-59 years) and the mean BMI was $23.3 \pm 5.3 \mathrm{~kg} / \mathrm{m}^{2}$ (range 14.8-33.8 $\mathrm{kg} / \mathrm{m}^{2}$ ). In the synthetic dural graft duraplasty group, the mean age was $34 \pm 13$ years (range 13-56 years) and the mean BMI was $23.3 \pm 4.1 \mathrm{~kg} / \mathrm{m}^{2}$ (range $18.5-33.8 \mathrm{~kg} / \mathrm{m}^{2}$ ). All patients underwent a full neurological examination. Brachial neuralgia, motor weakness, paresthesia, headaches, vomiting, scoliosis, and hoarseness were observed. Motor weakness was the most common symptom in both groups. Clinical characteristics and outcome details are listed in Table 2.

A comparison of the perioperative details is shown in Table 3. The mean overall operative time for the duraplasty in situ group was $4.9 \pm 1$ hours (range 3.5-7.0 hours) compared with $4.1 \pm 1$ hours (range 2.5-5.5 hours) for the synthetic dural graft duraplasty group. The mean EBL was $229 \pm 176 \mathrm{ml}$ (range 30-600 ml) in the duraplasty in situ group compared with $254 \pm 82 \mathrm{ml}$ (range $50-300 \mathrm{ml}$ ) in the synthetic dural graft duraplasty group. The mean LOS 

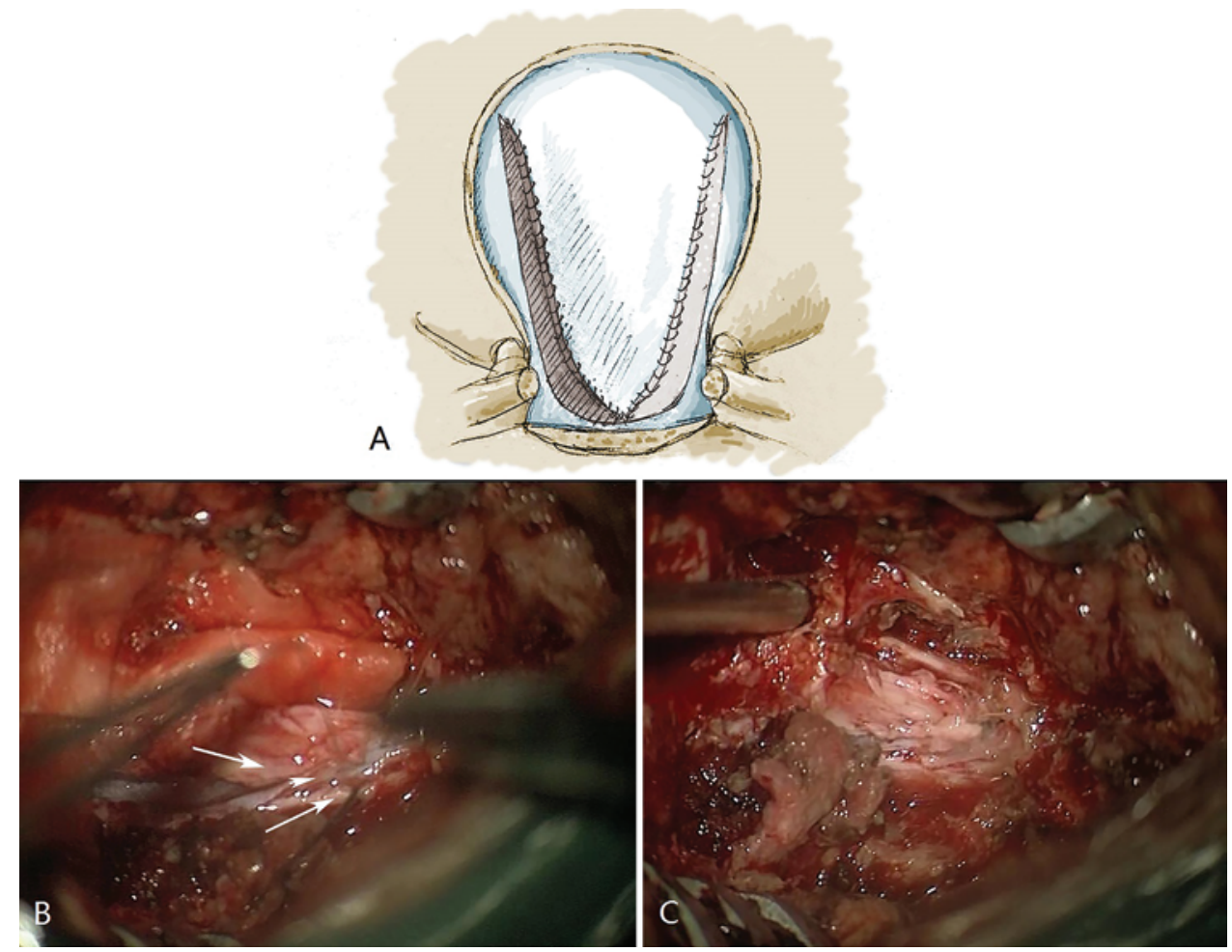

FIG. 3. Drawing and intraoperative photographs showing conclusion of duraplasty in situ procedure. A and B: The outer layer of the dura was sutured to the margin of the inner layer of the dura. Long white arrows indicate the outer layer of the dura; short white arrow indicates the inner layer of the dura. C: The completed duraplasty in situ. A: Copyright Lei Zhang. Published with permission. Figure is available in color online only.

after the operation was $13.5 \pm 8.2$ days (range 7-37 days) in the duraplasty in situ group compared with $12.8 \pm 6.0$ days (range 6-30 days) in the synthetic dural graft duraplasty group. The hospital cost was higher in the synthetic dural graft duraplasty group than in the duraplasty in situ group, and this difference was significant (mean CNY 29,385 vs CNY 23,354; $\mathrm{p}<0.05$; CNY $1=\mathrm{US} \$ 0.16$ ).

No surgical mortality or neurological aggravation oc- curred postoperatively. Fewer complications were encountered in the duraplasty in situ group than in the synthetic dural graft duraplasty group. In the in situ group, 1 patient had a fever on postoperative Day 8 and was diagnosed with bacterial meningitis after lumbar puncture. He was treated with antibiotics for 2 weeks and was discharged after his symptoms resolved and his laboratory test results were negative. One patient in the synthetic dural graft

TABLE 1. Patient demographic and clinical data*

\begin{tabular}{|c|c|c|c|}
\hline \multirow[b]{2}{*}{ Variable } & \multicolumn{2}{|c|}{ Duraplasty Technique } & \multirow[b]{2}{*}{$p$ Value } \\
\hline & In Situ $(n=13)$ & Synthetic Dural Graft $(n=14)$ & \\
\hline \multicolumn{4}{|l|}{ Sex } \\
\hline Male (\%) & $3(23.1)$ & $6(42.9)$ & 0.420 \\
\hline Female (\%) & $10(76.9)$ & $8(57.1)$ & \\
\hline Mean age in yrs (range) & $40 \pm 15(11-59)$ & $34 \pm 13(13-56)$ & 0.231 \\
\hline Mean height in cm (range) & $156.9 \pm 10.7(126-170)$ & $163.6 \pm 8.0(147-176)$ & 0.073 \\
\hline Mean weight in kg (range) & $58.1 \pm 15.1(24-75)$ & $62.4 \pm 10.7(40-78)$ & 0.398 \\
\hline Mean BMI (range) & $23.3 \pm 5.3(14.8-33.8)$ & $23.3 \pm 4.1(18.5-33.8)$ & 0.997 \\
\hline \multicolumn{4}{|l|}{ Symptoms \& signs } \\
\hline Brachial neuralgia & $1(7.7)$ & $2(14.3)$ & \\
\hline Motor weakness & $8(61.5)$ & $7(50)$ & \\
\hline Paresthesias & $4(30.8)$ & $2(14.3)$ & \\
\hline Headaches & $5(38.5)$ & $1(7.1)$ & \\
\hline Vomiting & $2(15.4)$ & $0(0)$ & \\
\hline Scoliosis & $0(0)$ & $2(14.3)$ & \\
\hline Hoarseness & $1(7.7)$ & $0(0)$ & \\
\hline
\end{tabular}

* Unless otherwise indicated, values represent numbers of cases (\%); mean values are given $\pm \mathrm{SD}$. 
TABLE 2. Patient characteristics and outcome details

\begin{tabular}{|c|c|c|c|c|c|c|}
\hline $\begin{array}{l}\text { Case } \\
\text { No. }\end{array}$ & $\begin{array}{c}\text { Sex, } \\
\text { Age (yrs) }\end{array}$ & Tx & Preop Symptoms \& Signs & $\begin{array}{l}\text { Syrinx on } \\
\text { Preop MRI }\end{array}$ & $\begin{array}{c}\text { Clinical } \\
\text { Outcomes }\end{array}$ & $\begin{array}{c}\text { Syrinx on 6-Mo } \\
\text { Postop MRI }\end{array}$ \\
\hline 1 & $\mathrm{M}, 11$ & DIS & Motor weakness, paresthesias & Yes & $\operatorname{Imp}$ & Stable \\
\hline 2 & $\mathrm{~F}, 50$ & DIS & Headache, vomiting & No & Stable & No \\
\hline 3 & $\mathrm{M}, 47$ & DIS & Brachial neuralgia, motor weakness, paresthesias & Yes & $\operatorname{Imp}$ & Stable \\
\hline 4 & $F, 56$ & DIS & Headache & Yes & Stable & Stable \\
\hline 5 & $F, 58$ & DIS & Motor weakness, paresthesias & Yes & Imp & Imp \\
\hline 6 & $\mathrm{~F}, 37$ & DIS & Motor weakness & Yes & Imp & Stable \\
\hline 7 & $\mathrm{M}, 30$ & DIS & Motor weakness & Yes & Imp & Imp \\
\hline 8 & $\mathrm{~F}, 59$ & DIS & Headache & No & Imp & No \\
\hline 9 & $\mathrm{~F}, 28$ & DIS & Paresthesias & Yes & Imp & Imp \\
\hline 10 & $F, 54$ & DIS & Motor weakness, headache, vomiting, hoarseness & Yes & Imp & Stable \\
\hline 11 & $F, 40$ & DIS & Headaches & No & Imp & No \\
\hline 12 & $F, 25$ & DIS & Motor weakness & Yes & Imp & Stable \\
\hline 13 & $\mathrm{~F}, 29$ & DIS & Motor weakness & Yes & Imp & Imp \\
\hline 14 & M, 24 & SDGD & Motor weakness & Yes & Imp & Imp \\
\hline 15 & M, 16 & SDGD & Scoliosis & Yes & Agg & Stable \\
\hline 16 & $F, 42$ & SDGD & Motor weakness & Yes & Imp & $\operatorname{Imp}$ \\
\hline 17 & M, 33 & SDGD & Motor weakness & Yes & Imp & Imp \\
\hline 18 & M, 26 & SDGD & Motor weakness & Yes & Imp & $\operatorname{Imp}$ \\
\hline 19 & $\mathrm{M}, 40$ & SDGD & Paresthesias & Yes & Imp & Stable \\
\hline 20 & $F, 22$ & SDGD & Motor weakness & Yes & Imp & Imp \\
\hline 21 & $F, 35$ & SDGD & Motor weakness & Yes & Imp & Stable \\
\hline 22 & $F, 49$ & SDGD & Headache & Yes & Imp & Stable \\
\hline 23 & $F, 32$ & SDGD & Motor weakness & Yes & Imp & Imp \\
\hline 24 & $\mathrm{~F}, 50$ & SDGD & Brachial neuralgia & Yes & Imp & Imp \\
\hline 25 & $F, 56$ & SDGD & Brachial neuralgia & Yes & Imp & Imp \\
\hline 26 & M, 34 & SDGD & Paresthesias & Yes & $\operatorname{Imp}$ & Stable \\
\hline 27 & $F, 13$ & SDGD & Scoliosis & Yes & Stable & Stable \\
\hline
\end{tabular}

Agg = aggravated; DIS = duraplasty in situ; Imp = improved; SDGD = synthetic dural graft duraplasty; Stable = stabilized; Tx = treatment.

group was also diagnosed with meningitis. This patient was treated by the same method and recovered in 4 days. Another patient in the synthetic dural graft group experienced a CSF leak. The leak was small, and it ceased spontaneously within 5 days without any neurological consequences. Pseudomeningocele or surgical-site infection did not occur in either group.

All patients were followed up in the outpatient clinic. In the duraplasty in situ group, neurological outcome improved in 11 of the 13 patients $(84.6 \%)$ and stabilized in 2 (15.4\%); none of the patients became worse. In the synthetic dural graft duraplasty group, 12 of the 14 patients $(85.7 \%)$ improved, 1 (7.1\%) remained stable, and 1 (7.1\%) grew worse. In the duraplasty in situ patients, MRI showed that syrinx size had improved in 4 of the 10 patients (40\%) and stabilized in $6(60 \%)$. In the synthetic dural graft duraplasty group, syrinx size improved in 8 of 14 patients $(57.1 \%)$ and remained stable in $6(42.9 \%)$. Grafting was successful in all patients in the synthetic dural graft duraplasty group. MRI data showed total decompression of the posterior fossa in all patients in both groups (Fig. 4). All 27 patients demonstrated improvement of preoperative symptoms and good wound healing.

\section{Discussion}

Here, we report a novel autologous duraplasty in situ technique for the treatment of CM-I. To our knowledge, this is the first study to describe the application of this procedure. The results of this study demonstrate that this novel procedure is comparable to synthetic dural graft duraplasty; moreover, its associated hospital costs were significantly lower than those of synthetic dural graft duraplasty.

Posterior fossa decompression is the standard surgical procedure for patients with CM-I. The dura is often expanded to allow further expansion of the posterior fossa. The creation of a watertight dural repair reduces the risk of CSF leakage. . $10,12,17$ There is still significant controversy regarding the most appropriate duraplasty method. Duraplasty can be performed using autologous tissues or commercially available dural patches. ${ }^{3,6}$ Nonautogenous grafts are easy to acquire but are associated with a wide range of complications including hemorrhage, transmission of bacterial and viral pathogens, fatal Creutzfeldt-Jakob disease transmission, foreign body reaction, systemic immune response, excessive scarring, slower wound healing, premature graft dissolution, and wound dehiscence., , $4-6,14,18,21,22^{2}$ 
TABLE 3. Perioperative details

\begin{tabular}{lccc}
\hline & \multicolumn{2}{c}{ Duraplasty Technique } & \\
\cline { 2 - 3 } Variable & In Situ $(\mathrm{n}=13)$ & Synthetic Dural Graft $(\mathrm{n}=14)$ & $\mathrm{p}$ Value \\
\hline Mean op time in hrs (range) & $4.9 \pm 1.0(3.5-7.0)$ & $4.1 \pm 1.0(2.5-5.5)$ & 0.070 \\
\hline Mean EBL in ml (range) & $229 \pm 176(30-600)$ & $254 \pm 82(50-300)$ & 0.159 \\
\hline Mean postop LOS in days (range) & $13.5 \pm 8.2(7-37)$ & $12.8 \pm 6.0(6-30)$ & 0.808 \\
\hline Mean hospital cost in CNY (range) & $23,354 \pm 7908(8012-37,063)$ & $29,385 \pm 6203(21,243-40,117)$ & $0.036^{*}$ \\
\hline Complication (\%) & & & $1(7.1)$ \\
\hline Meningitis & $1(7.7)$ & $1(7.1)$ \\
\hline CSF leak & 0 & 0 & 0 \\
\hline Pseudomeningocele & 0 & & \\
\hline Surgical-site infection & 0 & $12(85.7)$ \\
\hline Neurological outcome & $11(84.6)$ & $1(7.1)$ \\
\hline Improved & $2(15.4)$ & $1(7.1)$ \\
\hline Stabilized & $0(0)$ & \\
\hline Aggravated & & $8(57.1)$ \\
\hline Syrinx on 6-mo postop MRI & $6(42.9)$ \\
\hline Improved & $6(60)$ & $0(0)$ \\
\hline Stabilized & $0(0)$ &
\end{tabular}

* Statistically significant $(p<0.05)$.

In addition, they are associated with a high incidence of persistent CSF leaks, pseudomeningocele formation, aseptic meningitis, infection, and hydrocephalus., $, 11,15,16$

The limitations of the use of autologous tissues, such as autologous fascia lata, ligamentum nuchae, fat packings, and the pericranium, include the time-consuming nature of procedures using such tissues, harvest-site complications, insufficient tissue availability, and technical difficulty. ${ }^{11,13,19}$ Obtaining sufficient autogenous tissue requires a longer incision or a second incision, which is associated with pain and scarring. The formation of a long occipital incision increases the risk of injury to the occipital artery and the greater occipital nerves..$^{23,24}$

Although the literature does not strongly support the superiority of either autologous or nonautologous grafts,
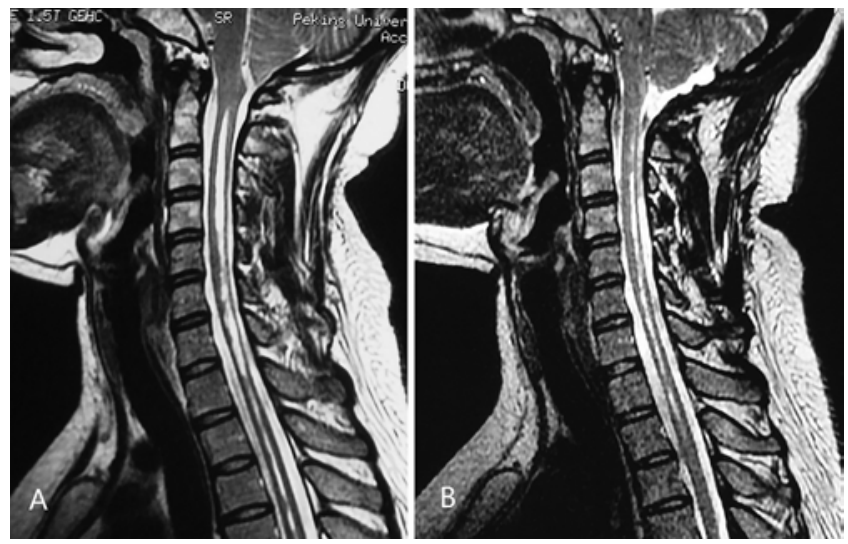

FIG. 4. Representative MR images of a patient treated with duraplasty in situ. A: Preoperative sagittal T2-weighted image of a patient with a symptomatic $\mathrm{CM}-\mathrm{I}$ demonstrating tonsillar herniation and syrinx. B: Postoperative image obtained at 6 -month follow-up demonstrating full resolution of the tonsillar herniation and improvement of syrinx. autologous tissue is recommended by many neurosurgeons when it is available and of good quality. ${ }^{1}$ Compared with the traditional duraplasty procedure, duraplasty in situ does not use nonautologous grafts and does not require an additional incision. Therefore, it is the least invasive technique for autologous duraplasty that has been developed so far. The results of this analysis demonstrate no significant differences between the 2 groups in overall operative time, complications, estimated blood loss, or duration of hospital stay after the operation. Based on our experience, we believe that our new procedure is as sufficient and safe as duraplasty with a synthetic dural graft.

The key to the success of this procedure is the separation of the outer and inner layers of the dura because the inner layer is much thinner than the outer layer and small vessels are distributed between these 2 layers. Therefore, the inner layer of the dura mater could be torn, causing bleeding. Overuse of bipolar coagulation may cause shrinkage of the dura. If the 2 layers are hard to separate or shrinkage of the dura makes suturing impossible, the procedure can be switched to one that involves a synthetic dural graft. According to our experience, a senior doctor can master this technique after approximately 5 to 7 cases. Consistent with our experience, Isu et al. reported good outcomes with their technique of bony foramen magnum decompression combined with removal of the outer layer of the dura mater. ${ }^{9}$

In China, artificial dural grafts account for a considerable proportion of hospital costs and are not yet fully covered by medical insurance. The results of our study demonstrate that this new procedure significantly reduces cost. Thus, patients who have economic difficulties will benefit from the cost-effectiveness of this procedure and be able to undergo the operation sooner. We believe this procedure is worth promoting, especially in developing countries.

The study is limited by several factors. First, the perfor- 
mance of this procedure by only 1 surgeon may introduce doubt regarding its repeatability; however, the use of a single surgeon also eliminated bias due to differences in surgeon expertise. Second, the size of our sample was small. The major limitation was the single-center retrospective design and the absence of long-term follow-up. These issues need to be resolved in future studies.

\section{Conclusions}

According to this study, duraplasty in situ has significantly lower hospital costs and a lower complication rate than duraplasty with a synthetic dural graft. We believe that duraplasty in situ is safe, feasible, and cost-effective for the treatment of CM-I. However, further investigation of this technique, with a larger sample size and long-term follow-up, is necessary.

\section{Acknowledgments}

We thank the entire staff of the Department of Neurosurgery, Peking University First Hospital, for their support with data collection and all colleagues who helped in the preparation of this paper.

\section{References}

1. Abla AA, Link T, Fusco D, Wilson DA, Sonntag VK: Comparison of dural grafts in Chiari decompression surgery: Review of the literature. J Craniovertebr Junction Spine 1:29-37, 2010

2. Alleyne $\mathrm{CH}$ Jr, Barrow DL: Immune response in hosts with cadaveric dural grafts. Report of two cases. J Neurosurg 81:610-613, 1994

3. Attenello FJ, McGirt MJ, Garcés-Ambrossi GL, Chaichana KL, Carson B, Jallo GI: Suboccipital decompression for Chiari I malformation: outcome comparison of duraplasty with expanded polytetrafluoroethylene dural substitute versus pericranial autograft. Childs Nerv Syst 25:183-190, 2009

4. Bejjani GK, Zabramski J: Safety and efficacy of the porcine small intestinal submucosa dural substitute: results of a prospective multicenter study and literature review. J Neurosurg 106:1028-1033, 2007

5. Costantino PD, Wolpoe ME, Govindaraj S, Chaplin JM, Sen $\mathrm{C}$, Cohen M, et al: Human dural replacement with acellular dermis: clinical results and a review of the literature. Head Neck 22:765-771, 2000

6. Danish SF, Samdani A, Hanna A, Storm P, Sutton L: Experience with acellular human dura and bovine collagen matrix for duraplasty after posterior fossa decompression for Chiari malformations. J Neurosurg 104 (1 Suppl):16-20, 2006

7. Djordjevic Z, Milosavlijevic B: Postoperative cerebrospinal fluid fistulas and their treatment. J Neurosurg Sci 18:109111,1974

8. Genitori L, Peretta P, Nurisso C, Macinante L, Mussa F: Chiari type I anomalies in children and adolescents: minimally invasive management in a series of 53 cases. Childs Nerv Syst 16:707-718, 2000

9. Isu T, Sasaki H, Takamura H, Kobayashi N: Foramen magnum decompression with removal of the outer layer of the dura as treatment for syringomyelia occurring with Chiari I malformation. Neurosurgery 33:845-850, 1993

10. Krieger MD, McComb JG, Levy ML: Toward a simpler surgical management of Chiari I malformation in a pediatric population. Pediatr Neurosurg 30:113-121, 1999

11. Lam FC, Kasper E: Augmented autologous pericranium duraplasty in 100 posterior fossa surgeries-a retrospective case series. Neurosurgery 71 (2 Suppl Operative):ons302ons307, 2012

12. Logue V, Edwards MR: Syringomyelia and its surgical treat- ment-an analysis of 75 patients. J Neurol Neurosurg Psychiatry 44:273-284, 1981

13. Malliti M, Page P, Gury C, Chomette E, Nataf F, Roux FX: Comparison of deep wound infection rates using a synthetic dural substitute (neuro-patch) or pericranium graft for dural closure: a clinical review of 1 year. Neurosurgery 54:599604, 2004

14. Martínez-Lage JF, Pérez-Espejo MA, Palazón JH, López Hernández F, Puerta P: Autologous tissues for dural grafting in children: a report of 56 cases. Childs Nerv Syst 22:139-144, 2006

15. Moskowitz SI, Liu J, Krishnaney AA: Postoperative complications associated with dural substitutes in suboccipital craniotomies. Neurosurgery 64 (3 Suppl):ons28-ons34, 2009

16. Nathoo N, Narotam PK: Posterior fossa duraplasty and hydrodynamic complications. Neurosurgery 66:E1030, 2010

17. Navarro R, Olavarria G, Seshadri R, Gonzales-Portillo G, McLone DG, Tomita T: Surgical results of posterior fossa decompression for patients with Chiari I malformation. Childs Nerv Syst 20:349-356, 2004

18. Noguchi-Shinohara M, Hamaguchi T, Kitamoto T, Sato T, Nakamura Y, Mizusawa H, et al: Clinical features and diagnosis of dura mater graft associated Creutzfeldt Jakob disease. Neurology 69:360-367, 2007

19. Ostendorf AP, Connolly AM: Medical management of eosinophilic meningitis following bovine graft duraplasty for Chiari malformation Type I repair: case report. J Neurosurg Pediatr 12:357-359, 2013

20. Parízek J, Mericka P, Nemecek S, Nemecková J, Spacek J, Suba P, et al: Posterior cranial fossa surgery in 454 children. Comparison of results obtained in pre-CT and CT era and after various types of management of dura mater. Childs Nerv Syst 14:426-439, 1998

21. Rosen DS, Wollman R, Frim DM: Recurrence of symptoms after Chiari decompression and duraplasty with nonautologous graft material. Pediatr Neurosurg 38:186-190, 2003

22. Simpson D, Robson A: Recurrent subarachnoid bleeding in association with dural substitute. Report of three cases. J Neurosurg 60:408-409, 1984

23. Stevens EA, Powers AK, Sweasey TA, Tatter SB, Ojemann RG: Simplified harvest of autologous pericranium for duraplasty in Chiari malformation Type I. Technical note. J Neurosurg Spine 11:80-83, 2009

24. Tubbs RS, Wellons JC III, Blount JP, Oakes WJ: Posterior atlantooccipital membrane for duraplasty. Technical note. J Neurosurg 97 (2 Suppl):266-268, 2002

25. Vanaclocha V, Saiz-Sapena N: Duraplasty with freeze-dried cadaveric dura versus occipital pericranium for Chiari type I malformation: comparative study. Acta Neurochir (Wien) 139:112-119, 1997

\section{Disclosures}

The authors report no conflict of interest concerning the materials or methods used in this study or the findings specified in this paper.

\section{Author Contributions}

Conception and design: Li, Yi. Acquisition of data: Zhang, Duan. Analysis and interpretation of data: Zhang. Drafting the article: Zhang. Critically revising the article: Yi. Reviewed submitted version of manuscript: Li. Approved the final version of the manuscript on behalf of all authors: Li. Statistical analysis: Zhang. Administrative/technical/material support: Duan. Study supervision: Yi.

\section{Correspondence}

Li Liang, Department of Neurosurgery, Peking University First Hospital, No. 8 Xishiku St., Xicheng District, Beijing 100034, China.email: lidoct@163.com. 